\title{
Oxidative stress in the brain causes hypertension via sympathoexcitation
}

\author{
Takuya Kishi ${ }^{1 *}$ and Yoshitaka Hirooka ${ }^{2}$ \\ 1 Department of Advanced Therapeutics for Cardiovascular Diseases, Kyushu University Graduate School of Medical Sciences, Fukuoka, Japan \\ ${ }^{2}$ Department of Advanced Cardiovascular Regulation and Therapeutics, Kyushu University Graduate School of Medical Sciences, Fukuoka, Japan
}

\author{
Edited by: \\ Ruy R. Campos, Federal University \\ of Sao Paulo, Brazil \\ Reviewed by: \\ Saurabh Aggarwal, Georgia Health \\ Sciences University, USA \\ Marcos Lopez, Fundación \\ Cardiovascular de Colombia, \\ Colombia \\ *Correspondence: \\ Takuya Kishi, Department of \\ Advanced Therapeutics for \\ Cardiovascular Diseases, Kyushu \\ University Graduate School of \\ Medical Sciences, 3-1-1 maidashi, \\ higashi-ku, Fukuoka 812-8582, \\ Japan. \\ e-mail:tkishi@cardiol.med.kyushu-u. \\ ac.jp
}

Activation of the sympathetic nervous system (SNS) has an important role in the pathogenesis of hypertension, and is determined by the brain. Previous many studies have demonstrated that oxidative stress, mainly produced by angiotensin II type $1\left(\mathrm{AT}_{1}\right)$ receptor and nicotinamide adenine dinucleotide phosphate (NAD $(P) H)$ oxidase, in the autonomic brain regions was involved in the activation of the SNS of hypertension. In this concept, we have investigated the role of oxidative stress in the rostral ventrolateral medulla (RVLM), which is known as the cardiovascular center in the brainstem, in the activation of the SNS, and demonstrated that $\mathrm{AT}_{1}$ receptor and NAD (P) H oxidase-induced oxidative stress in the RVLM causes sympathoexcitation in hypertensive rats. The mechanisms in which brain oxidative stress causes sympathoexcitation have been investigated, such as the interactions with nitric oxide (NO), effects on the signal transduction, or inflammations. Interestingly, the environmental factors of high salt intake and high calorie diet may also increase the oxidative stress in the brain, particularly in the RVLM, thereby activating the central sympathetic outflow and increasing the risk of hypertension. Furthermore, several orally administered $\mathrm{AT}_{1}$ receptor blockers have been found to cause sympathoinhibition via reduction of oxidative stress through the inhibition of central $A T_{1}$ receptor. In conclusion, we must consider that $A T_{1}$ receptor and the related oxidative stress production in the brain cause the activation of SNS in hypertension, and that $A T_{1}$ receptor in the brain could be novel therapeutic target of the treatments for hypertension.

Keywords: brain, oxidative stress, sympathetic nerve activity, hypertension, angiotensin II

\section{INTRODUCTION}

Recent many studies have suggested that sympathetic nervous system (SNS) is important in the pathogenesis, initial pathological events, development, and end organ damages of hypertension (Grassi, 2009, 2010; Esler, 2010; Grassi et al., 2010; Mauo et al., 2010). The activation of the SNS is determined by brain, especially by a rostral ventrolateral medulla (RVLM) in the brainstem (Dampney, 1994; Guyenet, 2006). The RVLM neurons determine the basal central sympathetic outflow and integrate the inputs from baroreceptors, chemoreceptors, and visceral receptors via the nucleus of the solitary tract (NTS) (Pilowsky and Goodchild, 2002; Dampney et al., 2003; Sved et al., 2003; Campos and Bergamschi, 2006; Guyenet, 2006; Carlson and Wyss, 2008), and it also receives the inputs from the paraventricular nucleus (PVN) of the hypothalamus, which is known as a key nucleus of the central cardiovascular regulation (Pilowsky and Goodchild, 2002; Dampney et al., 2005; Coote, 2007). Therefore, RVLM is known as a cardiovascular center.

The importance of systemic oxidative stress has already been determined in the various aspects of hypertension (Briones and Touyz, 2010). There are several studies with regard to the role of brain oxidative stress in the activation of the SNS and hypertension (Tai et al., 2005; Peterson et al., 2006; Hirooka, 2008,
2011; Campos, 2009; Hirooka et al., 2010, 2011). Among them, we have investigated the role of oxidative stress in the brain, particularly in the RVLM, in the pathogenesis of hypertension (Kishi et al., 2004, 2008, 2009, 2010a,b, 2011a, 2012a,b; Koga et al., 2008; Konno et al., 2008, 2012; Nozoe et al., 2008; Kishi and Sunagawa, 2011, 2012; Nishihara et al., 2012). Other investigators have also confirmed our initial observations, and other details have been further investigated. In this review, we describe the importance of oxidative stress in the brainstem, particularly in the RVLM, on the regulation of the SNS and its contribution to the pathophysiology of hypertension.

\section{OXIDATIVE STRESS IN THE RVLM CAUSES SYMPATHOEXCITATION IN HYPERTENSIVE RATS}

We have demonstrated that oxidative stress in the RVLM is increased and contributes to the neural mechanisms of hypertension in stroke-prone spontaneously hypertensive rats (SHRSPs) (Kishi et al., 2004, 2008, 2009, 2010b, 2012a,b; Kishi and Sunagawa, 2011, 2012) and spontaneously hypertensive rats (SHRs) (Koga et al., 2008; Nishihara et al., 2012). We also confirmed that a microinjection of tempol, a membranepermeable superoxide dismutase (SOD) mimetic, into the RVLM decreased blood pressure and heart rate in SHRSPs, but not 
in normotensive rats. Furthermore, we transfected adenovirus vectors encoding the MnSOD gene into the bilateral RVLM in SHRSPs. Overexpression of MnSOD in the RVLM decreased blood pressure, heart rate and urinary norepinephrine excretion in SHRSPs, but not in normotensive rats. We also found reduced SOD activity in the RVLM of SHRSPs compared with normotensive rats, which led to a decreased capability of scavenging superoxide anions. Together, our these findings indicate that oxidative stress in the RVLM increased blood pressure, which may have occurred via an activation of the SNS, and this mechanism was involved in the neural pathophysiology of hypertension in SHRSPs. Consistent with our observations, it was reported that increased superoxide anion in the RVLM contributed to hypertension in SHRs (Tai et al., 2005). We have also demonstrated that oxidative stress in the RVLM causes sympathoexcitaion in other several hypertensive models, such as, salt-induced hypertension (Koga et al., 2008), dietary-induced hypertension (Kishi et al., 2011a; Konno et al., 2012), and experimental jet lag (Kishi and Sunagawa, 2011). These results are consistent with previous studies of other investigators (Fujita et al., 2007; Nagae et al., 2009).

Interestingly, every intervention led to a similar extent of reduction of blood pressure and superoxide production in hypertensive rats. In our studies, the reduction of oxidative stress in the RVLM causes prominent sympathoinhibition. Overexpression of MnSOD (Kishi et al., 2004; Nishihara et al., 2012), or microinjection of tempol (Kishi et al., 2004; Koga et al., 2008; Konno et al., 2012) decreases the activation of the SNS with reduction of the oxidative stress in the RVLM. In addition, Oliveira-Sales et al suggested that sympathoexcitation in renovascular (two-kidney one-clip) hypertensive rats are associated with oxidative stress in the RVLM and PVN of the hypothalamus and with systemic oxidative stress (Oliveira-Sales et al., 2008, 2009). Because, the two-kidney and one-clip model is an angiotensin II-dependent hypertension model, it is not surprising that oxidative stress was increased in this model. However, it is important that the increased oxidative stress in the autonomic brain regions, such as, the RVLM and PVN of the hypothalamus, was involved in the activation of the SNS as one of the mechanisms of hypertension in this model. Moreover, a recent study found that oxidative stress in the RVLM had a major role in the enhanced central sympathetic outflow in the two-kidney one-clip hypertensive rats (OliveiraSales et al., 2010a). These results strongly suggest that the increase in oxidative stress in the RVLM is an important cause, not result, of the sympathoexcitation, which leads to hypertension.

\section{SOURCES OF OXIDATIVE STRESS IN THE RVLM}

As the sources of oxidative stress production in the brain, there are several candidates, such as, nicotinamide adenine dinucleotide phosphate (NAD $(\mathrm{P}) \mathrm{H}$ ) oxidase, xanthine oxidase, uncoupled nitric oxide synthase, and mitochondria (Hirooka, 2008, 2011; Hirooka et al., 2010, 2011). Among them, we demonstrated that the activation of the NAD (P) H oxidase through angiotensin II type $1\left(\mathrm{AT}_{1}\right)$ receptor had a major role in the oxidative stress production in the RVLM of SHRSPs (Nozoe et al., 2008; Kishi et al., 2010a, 2012b). Regional expression of the NAD (P) H oxidase has been demonstrated in the brain including the NTS and RVLM
(Infanger et al., 2006; Campese et al., 2007; Bai et al., 2009). Peripheral slow-pressor dose of angiotensin II in mice led to a gradual development of hypertension that was correlated with marked elevation in superoxide production (Zimmerman et al., 2004b). In this case, the authors emphasized the importance of the sub-fornical organ (SFO), in which the blood-brain barrier is lacking and $\mathrm{AT}_{1}$ receptor is rich. Angiotensinergic inputs in the SFO are delivered to the PVN of the hypothalamus, and then it sends the neural information to the RVLM neurons. Thus, the functional responses of the SFO to angiotensin II are the increases in drinking behavior and blood pressure via the activation of the SNS and vasopressin release. In addition, we showed that Rac1 activation occurs in the activation of NAD (P) H oxidase (Nozoe et al., 2007; Hirooka et al., 2010; Kishi et al., 2010b). Rac1 is a small $\mathrm{G}$ protein involved in integrating the intracellular transduction pathways toward NAD (P) $\mathrm{H}$ activation and requires lipid modifications to migrate from the cytosol to the cell membrane. The inhibition of Racl caused by the transfection of the adenovirus vectors encoding a dominant negative Racl into the RVLM or NTS decreased blood pressure, heart rate and urinary norepinephrine excretion in SHRSPs, but not in normotensive rats (Nozoe et al., 2007; Hirooka et al., 2010). The blockade of Racl translocation from cytosol to membrane in the RVLM of SHRSPs causes sympathoinhibition via inhibition of NAD $(\mathrm{P}) \mathrm{H}$ oxidase and oxidative stress (Kishi et al., 2010b). It was demonstrated that Nox2-containing NAD (P) H oxidase followed by an influx of $\mathrm{Ca}^{2+}$ via the L-type calcium channels was the source of the angiotensin II-induced oxidative stress production in the NTS neurons that were anterograde labeled from the vagal afferents (Wang et al., 2004, 2006). Because, azelnidipine could reduce oxidative stress in the RVLM of SHRSPs associated with sympathoinhibition, the inhibition of the $\mathrm{Ca}^{2+}$ channel in the RVLM may have reduced oxidative stress (Konno et al., 2008; Shinohara et al., 2012) Thus, our findings indicate that the activation of the Racl in the RVLM or NTS produces oxidative stress via the NAD (P) H oxidase in SHRSPs. In fact, it was demonstrated that the activation of the Rac1/NAD (P) $\mathrm{H}$ oxidase was required in the pressor and dipsogenic actions of angiotensin II in the brain (Zimmerman et al., 2004a)

The brain renin-angiotensin system is activated in hypertension and chronic heart failure with enhanced central sympathetic outflow (Hu et al., 2002; Reja et al., 2006; Leenen, 2007; Huang and Leenen, 2009; Zucker et al., 2009; Dupont and Brouwers, 2010) Aldosterone increases angiotensin-converting enzyme, $\mathrm{AT}_{1}$ receptor and oxidative stress in the PVN of the hypothalamus of salt-sensitive hypertension and ischemic heart failure (Huang et al., 2011). It has been determined that mitochondriaderived oxidative stress mediates sympathoexcitation induced by angiotensin II in the brain (Nozoe et al., 2007; Zimmerman and Zucker, 2009). Exogenously administered angiotensin II into the RVLM elicits the pressor response via activation of the SNS (Hirooka et al., 1997; Dampney et al., 2007) The inhibition of $\mathrm{AT}_{1}$ receptor in the RVLM by an $\mathrm{AT}_{1}$ receptor blocker reduces blood pressure with sympathoinhibition in hypertensive rats (Hirooka et al., 1997; Koga et al., 2008; Kishi et al., 2010a, 2011a, 2012a,b; Konno et al., 2012). We found that the overexpression of MnSOD attenuated the angiotensin II-induced pressor response and also 
suppressed the angiotensin II-induced oxidative stress production in the RVLM (Nozoe et al., 2008) A recent study also demonstrated that the oxidative stress-induced impairment of the mitochondrial electron transport chain complexes in the RVLM contribute to further chronic oxidative stress, thereby leading to augmented central sympathetic outflow and hypertension (Chan et al., 2009). All these results indicate that $\mathrm{AT}_{1}$ receptor/NAD (P) $\mathrm{H}$ oxidase would be a main source to produce the oxidative stress in the RVLM of hypertensive rats.

\section{MECHANISMS OF BRAIN OXIDATIVE STRESS-INDUCED SYMPATHOEXCITATION}

There is an interaction between superoxide and nitric oxide (NO). In the brain, NO inhibits the activation of the SNS (Kishi et al., 2001, 2002; Patel et al., 2001; Hirooka et al., 2003). We found that an increase in NO in the RVLM reduces blood pressure, heart rate, and the activation of the SNS in normotensive rats and SHRSPs (Kishi et al., 2001, 2002), and the magnitude of the decreases in these variables were greater in SHRSPs than in normotensive rats, suggesting a deficiency in the NO bioavailability in SHRSPs. There is a possibility that the deficiency in the NO bioavailability might be induced by oxidative stress. Furthermore, we demonstrated that that overexpression of inducible NO synthase (iNOS) in the RVLM elicited blood pressure elevation and sympathoexcitation in normotensive rats via increase in oxidative stress (Kimura et al., 2005). This may have been caused by the so-called uncoupling of the NO synthase function because of the deficiency of the precursor of L-arginine and/or the cofactor tetrahydrobiopterin. Importantly, we have found that the iNOS expression in the RVLM is enhanced in SHRs compared with normotensive rats, and the microinjection of iNOS blockers into the RVLM reduced blood pressure only in SHRs (Kimura et al., 2009). A recent study also suggested that the up-regulation of $\mathrm{AT}_{1}$ receptor and iNOS in the RVLM was important for the maintenance of high blood pressure and renal sympathetic activation in the twokidney one-clip hypertensive rats (Oliveira-Sales et al., 2010b).

In the relationship between superoxide and $\mathrm{NO}$, we should focus on the peroxynitrite formation, because the kinetics formation of peroxynitrite from superoxide and NO is strong (Zielonka et al., 2012). Actually, peroxynitrite in the RVLM has an excitotoxic effect (Zanzinger, 2002). A recent study suggested that reactive oxygen species and reactive nitrogen species, such as peroxynitrite, could dose-dependently regulate iNOS function, and that peroxynitrite reduces both $\mathrm{NO}$ and superoxide production via enzymatically iNOS dysfunction (Sun et al., 2010). Another report indicated that an interactive action between $\mathrm{NO}$ and superoxide in the RVLM via formation of peroxynitrite contributes to the un-sustained hypotensive effect of $\mathrm{NO}$ after overexpression of endothelial NO synthase in SHRs (Kung et al., 2008). The role of peroxynitrite from NO and superoxide in the brain on the regulation of the SNS should be further examined.

In the brain, the balance between excitatory and inhibitory amino acids determines the neural activity ( $\mathrm{Li}$ et al., 2002; Garthwaite, 2008). In hypertensive rats, inhibitory amino acid $\gamma$-amino butylic acid (GABA) in the RVLM is decreased (Kishi et al., 2002), which in part contributes to the activation of the SNS. NO in the RVLM increases GABA release (Kishi et al.,
2001). We consider that oxidative stress would reduce the release of GABA in the RVLM via deficiency in NO bioavailability, which might cause sympathoexcitation. Interestingly, we recently demonstrated that oxidative stress modulates the balance between excitatory amino acid glutamate and GABA in the RVLM of hypertensive rats (Nishihara et al., 2012).

We also have focused the signal transduction associated with oxidative stress. $\mathrm{AT}_{1}$ receptor activates caspase- 3 through the Ras/mitogen-activated protein kinase/extracellular signalregulated kinase (ERK) in the RVLM, which is involved in the sympathoexcitation in SHRSPs (Kishi et al., 2010a,b,c). The activities of Ras, p38 mitogen- activated protein kinase (MAPK), ERK and caspase-3 in the RVLM were elevated in SHRSPs compared with those in normotensive rats. The phosphorylation of the pro-apoptotic protein Bax and Bad, which releases cytochrome $c$ in the mitochondria, leads to caspase-3 activation (Kishi et al., 2010a,b,c). In contrast, the phosphorylation of the anti-apoptotic protein $\mathrm{Bcl}-2$ inhibits the caspase- 3 activation. Intracerebroventricular (ICV) infusion of a caspase-3 inhibitor reduces blood pressure, heart rate and the activation of the SNS in SHRSPs, but not in normotensive rats. ICV infusion of an $\mathrm{AT}_{1}$ receptor blocker also reduced blood pressure, heart rate, and activation of the SNS and also reduced the activities of Ras, p38 MAPK, ERK, and caspase-3 in the RVLM of SHRSPs, suggesting that these pathways exist downstream to the $\mathrm{AT}_{1}$ receptor activation in the RVLM of SHRSPs and are related to blood pressure elevation and sympathoexcitation of SHRSPs. In support of our findings, it was reported that the NAD (P) H oxidase derived superoxide anion mediates the activation of p38 MAPK or ERK but not the stress-activated protein kinase/Jun N-terminal kinase by angiotensin II in the RVLM and pressor response (Chan et al., 2005). Furthermore, in a later study, the authors suggested that the activation of the NAD (P) H oxidase/ERK in the RVLM induced the phosphorylation of the transcriptional factor cyclic adenosine monophosphate response element-binding protein and c-fos induction, thereby contributing to the long-term pressor response triggered by angiotensin II (Chan et al., 2007). It is also important to note that the activation of the activator protein 1 and the Jun $\mathrm{N}$-terminal kinase may occur in rabbits with rapid pacing-induced heart failure (Liu et al., 2006). Thus, the signaling pathway followed by the oxidative stress production may differ between hypertension and heart failure because of the advancement of the disease state.

Recently, the further central mechanisms of sympathoexcitation associated with oxidative stress are focused, such as, perivascular macrophages in the brain (Yu et al., 2010; Hirooka, 2010), neuron-astrocyte uncoupling (Kishi et al., 2010c, 2011b), transcription factor NF- $\kappa \mathrm{B}$ (Cardinale et al., 2011), or microglial cytokines (Shi et al., 2010) in the brain causes sympathoexcitation in hypertension and heart failure. Further studies are required to clarify these mechanisms.

\section{INFLUENCE OF SALT AND OBESITY ON OXIDATIVE STRESS IN THE BRAIN AND SYMPATHETIC NERVE ACTIVITY}

A high salt intake is an important environmental factor for the development of hypertension (Adrogue and Madias, 2007). Increasing evidence suggests that central nervous system 
mechanisms are involved in salt-induced hypertension, although, the kidney also has a key role in salt-induced hypertension (Brooks et al., 2005; Huang et al., 2006; Adams et al., 2007; Osborn et al., 2007). We also previously demonstrated that the increased $\mathrm{AT}_{1}$ receptor and NAD (P) $\mathrm{H}$ oxidase expression levels in the RVLM were responsible for the increased oxidative stress production and blood pressure in SHRs with a high salt intake compared with those with a regular salt intake (Koga et al., 2008). Consistent with our findings, increased oxidative stress was involved in the blood pressure elevation through an enhanced central sympathetic outflow in Dahl salt-sensitive rats (Fujita et al., 2007). It is possible that the enhanced neuronal activity in the PVN of the hypothalamus would augment the RVLM neuronal activity in these concepts.

It has also been demonstrated that the activation of the SNS has an important role in obesity-related hypertension, including the metabolic syndrome (Landsberg, 2001; Rahmouni et al., 2005; Esler et al., 2006; Grassi, 2006, 2007; Stocker et al., 2007). Insulin or leptin increases the activation of the SNS in obesity or metabolic syndrome (Rahmouni et al., 2005; Prior et al., 2010; Hilzendeger et al., 2012). In addition, it has been demonstrated that the RVLM neurons are activated in obesity-induced rats (Stocker et al., 2007). A previous study suggested that oxidative stress, particularly in the hypothalamus, was involved in the activation of the SNS in obesity-induced hypertensive rats (Nagae et al., 2009). Recently, we also have demonstrated that $\mathrm{AT}_{1}$ receptor/NAD (P) H oxidase-induced oxidative stress in the RVLM causes sympathoexcitation in obesity-induced hypertensive rats (Kishi et al., 2011a; Konno et al., 2012). Leptin is reported to have an interaction with brain renin-angiotensin system in the regulation of the SNS (Hilzendeger et al., 2012).

These findings with regard to the salt-induced and/or obesityinduced hypertension strongly suggest that oxidative stress in the RVLM is increased not only by gene background (such as in SHRSPs or SHRs) but also by environmental factor. A recent study reported the epigenetic alteration is occurred in saltinduced hypertension (Mu et al., 2011). There is a possibility that various genetic, environmental, and epigenetic factors affect the brain and causes sympathoexcitation via oxidative stress in the RVLM.

\section{EFFECTS OF AT 1 RECEPTOR BLOCKERS ON OXIDATIVE STRESS IN THE BRAIN AND SYMPATHETIC NERVE ACTIVITY}

As described above, the up-regulation of $\mathrm{AT}_{1}$ receptor in the brain has an important role in the pathophysiology of hypertension (Sved et al., 2003; Guyenet, 2006; Dupont and Brouwers, 2010) It is interesting to note that $\mathrm{AT}_{1}$ receptor is rich in the specific brain, such as, anteroventral third ventricle, PVN of the hypothalamus, NTS and RVLM in the brainstem (Allen et al., 1999; Hu et al., 2002; McKinley et al., 2003; Reja et al., 2006). It has been demonstrated that peripherally administered $\mathrm{AT}_{1}$ receptor blockers could penetrate the blood-brain barrier and blocks $\mathrm{AT}_{1}$ receptor within the brain as well as outside of the brain, although, the extent of the blocking action within the brain varies among $\mathrm{AT}_{1}$ receptor blockers when they are administered peripherally (Wang et al., 2003; Kishi et al., 2012b; Konno et al., 2012).
The peripheral treatment with $\mathrm{AT}_{1}$ receptor blockers attenuates or nearly blocks the pressor response to centrally administered angiotensin II (Tsuchihashi et al., 1999; Nishimura et al., 2000; Gohlke et al., 2001; Kishi et al., 2012b; Konno et al., 2012) This is also observed with the microinjection of angiotensin II into the RVLM in SHRs orally treated with olmesartan (Lin et al., 2005). Furthermore, the central nervous system blockade by the peripheral administration of $\mathrm{AT}_{1}$ receptor blockers has been documented by autoradiographic binding studies (Wang et al., 2003). It should be noted that the high density of $\mathrm{AT}_{1}$ receptor is present in brain regions that are involved in the regulation of the SNS such as the circumventricular organs (for example, the SFO, the organum vasculosum laminae terminalis, and area postrema) outside of the blood-brain barrier where peripherally administered $\mathrm{AT}_{1}$ receptor blockers are able to access without considering the existence of the blood-brain barrier as well as inside of the blood-brain barrier (McKinley et al., 2003). Recent studies suggest that the systemic administered $\mathrm{AT}_{1}$ receptor blockers also act on the $\mathrm{AT}_{1}$ receptor within the brain, thereby reducing blood pressure in hypertensive rats (Tsuchihashi et al., 1999; Leenen and Yuan, 2001; Lin et al., 2005; Araki et al., 2009; Hirooka et al., 2010; Kishi et al., 2012b; Konno et al., 2012). The extent of the actions of $\mathrm{AT}_{1}$ receptor blockers within the brain might depends partly on the lipophilicity and pharmacokinetics (Gohlke et al., 2001; Wang et al., 2003). Sympathoinhibitory effect via reduction of oxidative stress through the inhibition of the $\mathrm{AT}_{1}$ receptor in the brain is differed between $\mathrm{AT}_{1}$ receptor blockers. Orally administered telmisartan or olmesartan reduced blood pressure and urinary norepinephrine excretion in SHRSPs, and it was associated with a reduction of oxidative stress production in the brainstem including the RVLM (Araki et al., 2009; Hirooka et al., 2010). Orally administered telmisartan could inhibit $\mathrm{AT}_{1}$ receptor-induced oxidative stress in the RVLM and activation of the SNS in SHRSPs to a greater extent than candesartan, in spite of similar depressor effects (Kishi et al., 2012b). In obesity-induced hypertensive rats, telmisartan could also inhibit $\mathrm{AT}_{1}$ receptorinduced oxidative stress in the RVLM and activation of the SNS to a greater extent than losartan, in spite of similar depressor effects (Konno et al., 2012). Thus, it is conceivable that orally administered $\mathrm{AT}_{1}$ receptor blockers might block the $\mathrm{AT}_{1}$ receptor in the brain, particularly in the RVLM, thereby reducing the oxidative stress production and reducing blood pressure via inhibiting the activation of the SNS.

\section{SYMPATHOINHIBITION BY TARGETING BRAIN OXIDATIVE STRESS IN HYPERTENSION}

3-hydroxy-3-methylglutaryl coenzyme A reductase inhibitors (statins) are potent inhibitors of cholesterol biosynthesis. Interestingly, a previous study suggests that statins reduce blood pressure in patients with hypertension (Golomb et al., 2008). Moreover, the potential sympathoinhibition of statins has been demonstrated (Kishi et al., 2003; Sinski et al., 2009; Gomes et al., 2010; Kishi and Hirooka, 2010; Siddiqi et al., 2011). It has been demonstrated that statins have antioxidant effect (Wassmann et al., 2002). We have demonstrated that orally administered atorvastatin causes sympathoinhibition and improves the impaired baroreflex sensitivity via reduction 
of oxidative stress through the inhibition of $\mathrm{AT}_{1}$ receptor-NAD (P) $\mathrm{H}$ oxidase and up-regulation of MnSOD in the RVLM of SHRSPs (Kishi et al., 2008, 2009, 2010b). Other previous studies have demonstrated that simvastatin normalized the activation of the SNS in rabbits with heart failure (Pliquett et al., 2003; Gao et al., 2005). However, it has not been fully clarified whether the statin-induced sympathoinhibition via reduction of oxidative stress in the brain is a class-effect or not.

Several calcium channel blockers have been confirmed to cause sympathoinhibition via reduction of oxidative stress in hypertensive rats. Orally administered amlodipine (Hirooka et al., 2006) or azelnidipine (Konno et al., 2008) cause sympathoinhibition via reduction of oxidative stress in the RVLM of SHRSPs. We confirmed that orally administered azelnidipine inhibit the NAD (P) $\mathrm{H}$ oxidase activity and activate MnSOD in the RVLM of SHRSPs (Konno et al., 2008). These results are consistent with previous study (Umemoto et al., 2004). Furthermore, combination of atorvastatin and amlodipine (Kishi and Sunagawa, 2012) or combination of olmesartan and azelnidipine (Shinohara et al., 2012) has additive effects of sympathoinhibition via reduction of oxidative stress in the brain.

Interestingly, calorie restriction (Kishi et al., 2011a) or exercise training (Kishi et al., 2012a) has a pivotal role to cause sympathoinhibition via reduction of oxidative stress through the inhibition of the $\mathrm{AT}_{1}$ receptor in hypertensive rats. These results provide us the possibility that adipocytokines and/or insulin resistance might affect the brain $\mathrm{AT}_{1}$ receptor, and cause sympathoexcitation.

\section{PERSPECTIVES}

Figure shows our concept in the regulation of the activation of the SNS via brain renin-angiotensin system and oxidative stress (Figure 1). In the brain, particularly in the autonomic regulatory regions, such as the RVLM, NTS and PVN of the hypothalamus, previous studies have suggested that the inhibition of the brain $\mathrm{AT}_{1}$ receptor may have a significant role in the sympathoinhibitory effect via reduction of oxidative stress. $\mathrm{AT}_{1}$ receptor blockers are widely used in the treatments for hypertension (Iwanami et al., 2009). It is also suggested that $\mathrm{AT}_{1}$ receptor blockers may have protective effects on neurons, reducing the incidence of stroke and improving cognition (Iwanami et al., 2009; Mogi and Horiuchi, 2009). In addition, renal afferent nerves may also contribute to the blood pressure elevation according to the recent findings of the renal nerve ablation in

\section{REFERENCES}

Adams, J. M., Madden, C. J., Sved, A. F., and Stocker, S. D. (2007). Increased dietary salt enhances sympathoexcitatory and sympathoinhibitory responses from the rostral ventrolateral medulla. Hypertension 50, 354-359.

Adrogue, H. J., and Madias, N. E. (2007). Sodium and potassium in the pathogenesis of hypertension. N. Engl. J. Med. 356, 1966-1978.

Allen, A. M., MacGregor, D. P., McKinley, M. J., and Mendelsohn,
F. A. O. (1999). Angiotensin II receptors in the human brain. Regul. Pept. 79, 1-7.

Araki, S., Hirooka, Y., Kishi, T., Yasukawa, K., Utsumi, H., and Sunagawa, K. (2009). Olmesartan reduces stress in the brain of stroke-prone spontaneously hypertensive rats assessed by an in vivo ESR method. Hypertens. Res. 32, 1091-1096.

Bai, Y., Jabbari, B., Ye, S., Campese, V. M., and Vaziri, N. D. (2009). Regional expression of $\mathrm{NAD}(\mathrm{P}) \mathrm{H}$

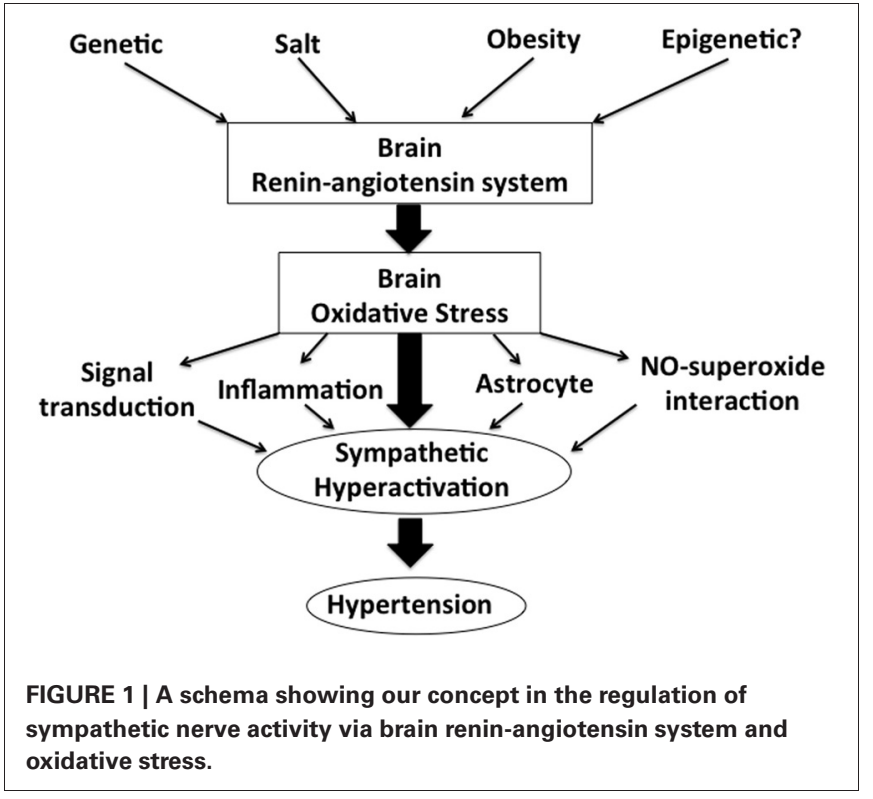

patients with resistant hypertension (Krum et al., 2009; DiBona and Esler, 2010; Simplicity HTN-2 Investigators, 2010). Renal afferent nerves project directly into many areas in the central nervous system controlling the activation of the SNS such as the NTS and hypothalamus (Calaresu and Ciriello, 1981; Ciriello and Calaresu, 1983; Stella et al., 1987). It is demonstrated that oxidative stress mediates the stimulation of the SNS in the phenol renal injury model of hypertension in which the renal afferent nerves are stimulated (Ye et al., 2006). In this model, brain $\mathrm{AT}_{1}$ receptor and NAD (P) H oxidase are activated. Previous studies have suggested that the increased oxidative stress production and reduced neuronal NOS expression may be involved in this mechanisms, which leads to the alteration of cytokines in the brain (Campese et al., 2005; Ye et al., 2006). It is interesting and important to consider that $\mathrm{AT}_{1}$ receptor and related oxidative stress production in the brain are as novel therapeutic targets of the treatments for hypertension.

\section{ACKNOWLEDGEMENTS}

This study was supported by a Grant-in-Aid for Scientific Research from the Japan Society for the Promotion of Science (15590757, 17590745, 19390231, and 22790709) and, in part, a Kimura Memorial Foundation Research Grant.

oxidase and superoxide dismutase in the brain of rats with neurogenic hypertension. Am. J. Nephrol. 29, 483-492.

Briones, A. M., and Touyz, R. M. (2010). Oxidative stress and hypertension: current concepts. Curr. Hypertens. Rep. 12, 135-142.

Brooks, V. L., Haywood, J. R., and Johnson, A. K. (2005). Translation of salt retention to central activation of the sympathetic nervous system in hypertension. Clin. Exp. Pharmacol. Physiol. 32, 426-432.
Calaresu, F. R., and Ciriello, J. (1981). Renal afferent nerves affect discharge rate of medullary and hypothalamic single units in cat. J. Auton. Nerv. Syst. 3, 311-320.

Campese, V. M., Shaohua, Y., and Huiquin, Z. (2005). Oxidative stress mediates angiotensin II-dependent stimulation of sympathetic nerve activity. Hypertension 46, 533-539.

Campese, V. M., Sindhu, R. K., Ye, S., Bai, Y., Vaziri, N. D., and Jabbari, B. (2007). Regional expression of $\mathrm{NO}$ synthase, $\mathrm{NAD}(\mathrm{P}) \mathrm{H}$ oxidase 
and superoxide dismutase in the rat brain. Brain Res. 1134, 27-32.

Campos, R. R. (2009). Oxidative stress in the brain and arterial hypertension. Hypertens. Res. 32, 1047-1048.

Campos, R. R., and Bergamschi, C. T. (2006). Neurotransmission alterations in central cardiovascular control in experimental hypertension. Curr. Hypertens. Rev. 2, 193-198.

Cardinale, J. P., Sriramula, S., Mariappan, N., Agarwal, D., and Francis, J. (2011). Angiotensin II-induced hypertension hypertension is modulated by nuclear factor- $\mathrm{kB}$ in the paraventricular nucleus. Hypertension 59, 113-121.

Carlson, S. H., and Wyss, J. M. (2008). Neurohormonal regulation of the sympathetic nervous system: new insights into central mechanisms of action. Curr. Hypertens. Rep. 10, 233-240.

Chan, S. H. H., Hsu, K. S., Huang, C. C., Wang, L. L., Ou, C. C., and Chan, J. Y. H. (2005). NADPH oxidasederived superoxide anion mediates angiotensin II-induced pressor effect via activation of p38mitogenactivated protein kinase in the rostral ventrolateral medulla. Circ. Res. 97, 772-780.

Chan, S. H. H., Wang, L. L., Tseng, H. L., and Chan, J. Y. H. (2007). Upregulation of AT1 receptor gene on activation of protein kinase $\mathrm{Cb} /$ nicotinamide adenine dinucleotide disphosphate oxidase/ ERK1/2/c-fos signaling cascade mediates long-term pressor effect of angiotensin II in rostral ventrolateral medulla. J. Hypertens. 25, 1845-1861.

Chan, S. H. H., Wu, K. L. H., Chang, A. Y. W., Tai, M. H., and Chan, J. Y. H. (2009). Oxidative impairment of mitochondrial electron transport chain complexes in rostral ventrolateral medulla contributes to neurogenic hypertension. Hypertension $53,217-227$

Ciriello, J., and Calaresu, F. R. (1983). Central projection of afferent renal fibers in the rat: an antegrade transport study of horseradish peroxidase. J. Auton. Nerv. Syst. 8, 273-285.

Coote, J. H. (2007). Landmarks in understanding the central nervous control of the cardiovascular system. Exp. Physiol. 92, 3-18.

Dampney, R. A. L. (1994). Functional organization of central pathways regulating the cardiovascular system. Physiol. Rev. 74, 323-364.

Dampney, R. A. L., Horiuchi, J., Killinger, S., Sheriff, M. J., Tan, P. S. P., and McDowall, L. M. (2005). Long-term regulation of arterial blood pressure by hypothalamic nuclei: some critical questions. Clin. Exp. Pharmacol. Physiol. 32, 419-425.

Dampney, R. A. L., Polson, J. W., Potts, P. D., Hirooka, Y., and Horiuchi, J. (2003). Functional organization of brain pathways subserving the baroreceptor reflex: studies in conscious animals using immediate early gene expression. Cell. Mol. Neurobiol. 23, 597-616.

Dampney, R. A. L., Tan, P. S. P., Sheriff, M. J., Fontes, M. A. P., and Horiuchi, J. (2007). Cardiovascular effects of angiotensin II in the rostral ventrolateral medulla: the push-pull hypothesis. Curr. Hypertens. Rep. 9, 222-227.

DiBona, G. F., and Esler, M. (2010). Translational medicine: the antihypertensive effect of renal denervation. Am. J. Physiol. 298, R245-R253.

Dupont, A. G., and Brouwers, S. (2010). Brain angiotensin peptides regulate sympathetic tone and blood pressure. J. Hypertens. 28, 1599-1610.

Esler, M. (2010). The 2009 Carl Ludwig lecture: pathophysiology of the human sympathetic nervous system in cardiovascular diseases: the transition from mechanisms to medical management. J. Appl. Physiol. 108, 227-237.

Esler, M., Straznicky, N., Eikelis, N., Masuo, K., Lambert, G., and Lambert, E. (2006). Mechanisms of sympathetic activation in obesityrelated hypertension. Hypertension 48, 787-796.

Fujita, M., Ando, K., Nagae, A., and Fujita, T. (2007). Sympathoexcitation by oxidative stress in the brain mediates arterial pressure elevation in salt-sensitive hypertension. Hypertension 50, 360-367.

Gao, L., Wang, W., Li, Y. L., Schultz, H. D., Liu, D., Cornish, K. G., and Zucker, I. H. (2005). Simvastatin therapy normalizes sympathetic neural control in experimental heart failure. Circulation 112, 1763-1770.

Garthwaite, J. (2008). Concepts of neural nitric oxide-mediated transmission. Eur. J. Neurosci. 27, 2783-2802.

Gohlke, P., Weiss, S., Jansen, A. Wienen, W., Stangier, J., Rascher, W., Culman, J., and Unger, T. (2001). AT1 receptor antagonist telmisartan administered peripherally inhibits central responses to angiotensin II in conscious rats. J. Pharmacol. Exp. Ther. 298, 62-70.

Golomb, B. A., Dimsdale, J. E., White, H. L., Ritchie, J. B., and Criqui, M. H. (2008). Reduction in blood pressure with statins: results from the USCD statin study, a randomized trial. Arch. Intern. Med. 168, 721-727.

Gomes, M. E., Tack, C. J., Verheugt, F. W., Smiths, P., and Lenders, J. W. M. (2010). Sympathoinhibition by atorvastatin in hypertensive patients. Circ. J. 74, 2622-2626.

Grassi, G. (2006). Sympathetic overdrive and cardiovascular risk in the metabolic syndrome. Hypertens. Res. 29, 839-847.

Grassi, G. (2007). Adrenergic overdrive as the link among hypertension, obesity, and impairedthermogenesis: lights and shadows. Hypertension 49, 5-6.

Grassi, G. (2009). Assessment of sympathetic cardiovascular drive in human hypertension:achievements and perspectives. Hypertension 54 690-697.

Grassi, G. (2010). Sympathetic neural activity in human hypertension and related diseases. Am. J. Hypertens. 23, 1052-1060.

Grassi, G., Seravalle, G., and QuartiTrevano, F. (2010). The 'neurogenic hypothesis' in hypertension: current evidence. Exp. Physiol. 95, 581-586.

Guyenet, P. G. (2006). The sympathetic control of blood pressure. Nat. Rev. Neurosci. 7, 335-346.

Hilzendeger, A. M., Morgan, D. A., Brooks, L., Dellsperger, D., Liu, X., Grobe, J. L., Raumouni, K., Sigmund, C. D., and Mark, A. L. (2012). A brain leptin-renin angiotensin system interaction in the regulation of sympathetic nerve activity. Am. J. Physiol. 302, H197-H206.

Hirooka, Y. (2008). Role of reactive oxygen species in brainstem in neural mechanisms of hypertension. Auton. Neurosci. 142, 20-24.

Hirooka, Y. (2010). Brain perivascular macrophages and central sympathetic activation after myocardial infarction: heart and brain interaction. Hypertension 55, 610-611.

Hirooka, Y. (2011). Oxidative stress in the cardiovascular center has a pivotal role in the sympathetic activation in hypertension. Hypertens. Res. $34,407-412$.

Hirooka, Y., Kimura, Y., Nozoe, M., Sagara, Y., Ito, K., and Sunagawa K. (2006). Amlodipine-induced reduction of oxidative stress in the brain is associated with sympathoinhibitory effects in stroke-prone spontaneously hypertensive rats. Hypertens. Res. 29, 49-56.

Hirooka, Y., Kishi, T., Sakai, K. Shimokawa, H., and Takeshita, A. (2003). Effects of overproduction of nitric oxide in the brain stem on the cardiovascular response in conscious rats. J. Cardiovasc Pharmacol. 41(Suppl. 1), S119-S126.

Hirooka, Y., Kishi, T., Sakai, K. Takeshita, A., and Sunagawa, K. (2011). Imbalance of central nitric oxide and reactive oxygen species in the regulation of sympathetic activity and neural mechanisms of hypertension. Am. J. Physiol. 300, R818-R826.

Hirooka, Y., Potts, P. D., and Dampney, R. A. L. (1997). Role of angiotensin II receptor subtypes in mediating the sympathoexcitatory effects of exogenous and endogenous angiotensin peptides in the rostral ventrolateral medulla. Brain Res. 772, 107-114.

Hirooka, Y., Sagara, Y., Kishi, T., and Sunagawa, K. (2010). Oxidative stress and central cardiovascular regulation: pathogenesis of hypertension and therapeutic aspects. Circ. J. 274, 827-835.

Hu, L., Zhu, D. N., Yu, Z., Wang, J. Q., Sun, Z. J., and Yao, T. (2002). Expression of angiotensin type 1 (AT1) receptor in the rostral ventrolateral medulla in rats. J. Appl. Physiol. 92, 2153-2161.

Huang, B. S., Amin, S., and Leenen, F. H. H. (2006). The central role of the brain in salt-sensitive hypertension. Curr. Opin. Cardiol. 21, 295-304.

Huang, B. S., and Leenen, F. H H. (2009). The brain reninangiotensin-aldosterone system: a major mechanism for sympathetic hyperactivity and left ventricular remodeling and dysfunction after myocardial infarction. Curr. Heart Fail. Rep. 6, 81-88.

Huang, B. S., Zheng, H., Tan, J., Patel, K. P., and Leenen, F. H. H. (2011) Regulation of hypothalamic reninangiotensin system and oxidative stress by aldosterone. Exp. Physiol. 96, 1028-1038.

Infanger, D. W., Shrama, R. V., and Davisson, R. L. (2006). NADPH oxidases of the brain: distribution, regulation, and function. Antioxid. Redox Signal. 8, 1583-1596.

Iwanami, J., Mogi, M., Iwai, M., and Horiuchi, M. (2009). Inhibition of the renin-angiotensin system and target organ protection. Hypertens. Res. 32, 229-237.

Kimura, Y., Hirooka, Y., Kishi, T., Ito, K., Sagara, Y., and Sunagawa, K. (2009). Role of inducible nitric oxide synthase in rostral ventrolateral medulla in blood pressure regulation in spontaneously hypertensive rats. Clin. Exp. Hypertens. 31, 281-286.

Kimura, Y., Hirooka, Y., Sagara, Y., Ito, K., Kishi, T., Shimokawa, H., 
Takeshita, A., and Sunagawa, K. (2005). Overexpression of inducible nitric oxide synthase in rostral ventrolateral medulla causes hypertension and sympathoexcitation via an increase in oxidative stress. Circ. Res. 96, 252-260.

Kishi, T., and Hirooka, Y. (2010). Sympathoinhibitory effects of atorvastatin in hypertension. Circ. J. 74, 2552-2553.

Kishi, T., Hirooka, Y., Ito, K., Sakai, K., Shimokawa, H., and Takeshita, A. (2002). Cardiovascular effects of overexpression of endothelial nitric oxide synthase in the rostral ventrolateral medulla in strokeprone spontaneously hypertensive rats. Hypertension 39, 264-268.

Kishi, T., Hirooka, Y., Katsuki, M., Ogawa, K., Shinohara, K., Isegawa, K., and Sunagawa, K. (2012a). Exercise training causes sympathoinhibition through antioxidant effect in the rostral ventrolateral medulla of hypertensive rats. Clin. Exp. Hypertens. 34, 278-283.

Kishi, T., Hirooka, Y., and Sunagawa, K. (2012b). Sympathoinhibition caused by orally administered telmisartan through inhibition of $\mathrm{AT}(1)$ receptor in the rostral ventrolateral medulla. Hypertens. Res. doi: 10.1038/hr.2012.63. [Epub ahead of print].

Kishi, T., Hirooka, Y., Kimura, Y., Ito, K., Shimokawa, H., and Takeshita, A. (2004). Increased reactive oxygen species in rostral ventrolateral medulla contributes to neural mechanisms of hypertension in strokeprone spontaneously hypertensive rats. Circulation 109, 2357-2362.

Kishi, T., Hirooka, Y., Konno, S., Ogawa, K., and Sunagawa, K. (2010a). Angiotensin II type 1 receptor activated caspase-3 through ras/mitogen-activated protein kinase/extracellular signal regulated kinase in the rostral ventrolateral medulla is involved in sympathoexcitation in stroke-prone spontaneously hypertensive rats. Hypertension 55, 291-297.

Kishi, T., Hirooka, Y., Konno, S., and Sunagawa, K. (2010b). Sympathoinhibition induced by centrally administered atorvastatin is associated with alteration of $\mathrm{NAD}(\mathrm{P}) \mathrm{H}$ oxidase and $\mathrm{Mn}$ superoxide dismutase activity in rostral ventrolateral medulla of stroke-prone spontaneously hypertensive rats. $J$. Cardiovasc. Pharmacol. 55, 184-190.

Kishi, T., Hirooka, Y., and Sunagawa, K. (2010c). Autoimplantation of astrocytes into cardiovascular center of brainstem causes sympathoinhibition and decreases the mortality rate in hypertensive rats. Circulation 122, A13856.

Kishi, T., Hirooka, Y., Konno, S., and Sunagawa, K. (2009). Atorvastatin improves the impaired baroreflex sensitivity via anti-oxidant effect in the rostral ventrolateral medulla of SHRSP. Clin. Exp. Hypertens. 31, 698-704.

Kishi, T., Hirooka, Y., Mukai, Y., Shimokawa, H., and Takeshita, A. (2003). Atorvastatin causes depressor and sympathoinhibitory effects with upregulation of nitric oxide synthase in stroke-prone spontaneously hypertensive rats. J. Hypertens. 21, 379-386.

Kishi, T., Hirooka, Y., Ogawa, K., Konno, S., and Sunagawa, K. (2011a). Calorie restriction inhibits sympathetic nerve activity via anti-oxidant effect in the rostral ventrolateral medulla of obesityinduced hypertensive rats. Clin. Exp. Hypertens. 33, 240-245.

Kishi, T., Hirooka, Y., and Sunagawa, K. (2011b). Autoimplantation of astrocytes into the cardiovascular center of brainstem causes sympathoinhibition and decreases the mortality rate in myocardial infarction-induced heart failure. Circulation 124, A11489.

Kishi, T., Hirooka, Y., Sakai, K., Shigematsu, H., Shimokawa, H., and Takeshita, A. (2001). Overexpression of eNOS in the RVLM causes hypotension and bradycardia via GABA release. Hypertension 38, 896-901.

Kishi, T., Hirooka, Y., Shimokawa, H., Takeshita, A., and Sunagawa, K. (2008). Atorvastatin reduced oxidative stress in the rostral ventrolateral medulla of stroke-prone spontaneously hypertensive rats. Clin. Exp. Hypertens. 30, 3-11.

Kishi, T., and Sunagawa, K. (2011). Experimental 'jet lag' causes sympathoexcitation via oxidative stress through AT1 receptor in the brainstem. Conf. Proc. IEEE Eng. Med. Biol. Soc. 2011, 1969-1972.

Kishi, T., and Sunagawa, K. (2012). Combination therapy of atorvastatin and amlodipine inhibits sympathetic nervous system activation and improves cognitive function in hypertensive rats. Circ. J. 76, 1934-1941.

Koga, Y., Hirooka, Y., Araki, S., Nozoe, M., Kishi, T., and Sunagawa, K. (2008). High salt intake enhances blood pressure increase during development of hypertension via oxidative stress in rostral ventrolateral medulla of spontaneously hypertensive rats. Hypertens. Res. 31, 2075-2083.
Konno, S., Hirooka, Y., Araki, S., Koga, Y., Kishi, T., and Sunagawa, K. (2008). Azelnidipine decreases sympathetic nerve activity via antioxidant effect in the rostral ventrolateral medulla of strokeprone spontaneously hypertensive rats. J. Cardiovasc. Pharmacol. 52, 555-560.

Konno, S., Hirooka, Y., Kishi, T., and Sunagawa, K. (2012). Sympathoinhibitory effect of telmisartan through the reduction of oxidative stress in rostral ventrolateral medulla of obesity-induced hypertensive rat. J. Hypertens. [Epub ahead of print].

Krum, H., Schlaich, M. P., Whitbourn, R., Sobotka, P., Sadowski, J., Bartus, K., Kapelak, B., Walton, A., Sievert, H., Thambar, S. Abraham, W. T., and Esler, M. (2009). Catheter-based renal sympathetic denervation for resistant hypertension: a multicentre safety and proof-of principle cohort study. Lancet 373, 1275-1281.

Kung, L. C., Chan, S. H., Wu, K. L., Ou, C. C., Tai, M. H., and Chan, J. Y. (2008). Mitochondrial respiratory enzyme complexes in rostral ventrolateral medulla as cellular targets of nitric oxide and superoxide interaction in the antagonism of antihypertensive action of eNOS transgene. Mol. Pharmacol. 74, 1319-1332.

Landsberg, L. (2001). Insulin-mediated sympathetic stimulation: role in the pathogenesis ofobesity-related hypertension (or, how insulin affects blood pressure, and why) J. Hypertens. 19, 523-528.

Leenen, F. H. H. (2007). Brain mechanisms contributing to sympathetic hyperactivity and heart failure. Circ. Res. 101, 221-223.

Leenen, F. H. H., and Yuan, B. (2001). Prevention of hypertension by irbesartan in Dahl S rats relates to central angiotensin II type 1 receptor blockade. Hypertension 37, 981-984.

Li, D. P., Chen, S. R., and Pan, H. L. (2002). Nitric oxide inhibits spinally projecting paraventricular neurons through potentiation of presynaptic GABA release. J. Neurophysiol. 88 , 2664-2674.

Lin, Y., Matsumura, K., Kagiyama, S. Fukuhara, M., Fujii, K., and Iida, M. (2005). Chronic administration of olmesartan attenuates the exaggerated pressor response to glutamate in the rostral ventrolateral medulla of SHR. Brain Res. 1058, 161-166.

Liu, D., Gao, L., Roy, S. K., Cornish, K. G., and Zucker, I. H. (2006). Neuronal angiotensin II type 1 receptor upregulation in heart failure: activation of activator protein
1 and Jun N-terminal kinase. Circ. Res. 99, 1004-1011.

Mauo, K., Lambert, G. W., Esler, M. D., Rakugi, H., Ogihara, T., and Schlaich, M. P. (2010). The role of sympathetic nervous system activity in renal injury and end-stage renal disease. Hypertens. Res. 33, 521-528.

McKinley, M. J., Albiston, A. L., Allen, A. M., Mathai, M. L., May, C. N., McAllen, R. M., Oldfield, B. J., Mendelsohn, F. A. O., and Chai, S. Y. (2003). The brain renin-angiotensin system: location and physiological roles. Int. J. Biochem. Cell Biol. 35, 901-918.

Mogi, M., and Horiuchi, M. (2009). Effects of angiotensin II receptor blockers on dementia. Hypertens. Res. 32, 738-740.

Mu, S., Shimosawa, T., Ogura, S., Wang, H., Uetake, Y., KawakamiMori, F., Marumo, T., Yatomi, Y., Geller, D. S., Tanaka, H., and Fujita, T. (2011). Epigenetic modulation on the renal $\beta$-adrenergic-WNK4 pathway in salt-sensitive hypertension. Nat. Med. 17, 573-580.

Nagae, A., Fujita, M., Kawarazaki, H., Matsui, H., Ando, K., and Fujita, T. (2009). Sympathoexcitation by oxidative stress in the brain mediates arterial pressure elevation in obesity-induced hypertension. Circulation 119, 978-986.

Nishihara, M., Hirooka, Y., Matsukawa, R., Kishi, T., and Sunagawa, K. (2012). Oxidative stress in the rostral ventrolateral medulla modulates excitatory and inhibitory inputs in spontaneously hypertensive rats. J. Hypertens. 30, 97-106.

Nishimura, Y., Ito, T., Hoe, K. L. and Saavedra, J. M. (2000). Chronic peripheral administration of the angiotensin II AT1 receptor antagonist candesartan blocks brain AT1 receptors. Brain Res. 871, 29-38.

Nozoe, M., Hirooka, Y., Koga, Y., Araki, S., Konno, S., Kishi, T. Ide, T., and Sunagawa, K. (2008). Mitochondria-derived reactive oxygen species mediate sympathoexcitation induced by angiotensin II in the rostral ventrolateral medulla. J. Hypertens. 26, 2176-2184.

Nozoe, M., Hirooka, Y., Koga, Y. Sagara, Y., Kishi, T., Engelhardt, J. F., and Sunagawa, K. (2007). Inhibition of Rac1-derived reactive oxygen species in nucleus tractus solitarius decreases blood pressure and heart arte in stroke-prone spontaneously hypertensive rats. Hypertension 50, $62-68$.

Oliveira-Sales, E. B., Colombari, D. S. A., Davisson, R. L., Kasparov, S., Hirata, A. E., Campos, R. R., and 
Paton, J. F. R. (2010a). Kidneyinduced hypertension depends on superoxide signaling in the rostral ventrolateral medulla. Hypertension 56, 290-296.

Oliveira-Sales, E. B., Nishi, E. E., Boim, M. A., Dolnikoff, M. S., Bergamaschi, C. T., and Campos, R. R. (2010b). Upregulation of AT1R and iNOS in the rostral ventrolateral medulla (RVLM) is essential for the sympathetic hyperactivity and hypertension in the $2 \mathrm{~K}-1 \mathrm{C}$ Wistar rat model. Am. J. Hypertens. 23, 708-715.

Oliveira-Sales, E. B., Dugaich, A. P., Carillo, B. A., Abreu, N. P., Boim, M. A., Martins, P. J., D'Ameida, V., Dolnkoff, M. S., Bergamaschi, C. T., and Campos, R. R. (2008). Oxidative stress contributes to renovascular hypertension. Am. J. Hypertens. 21, 98-104.

Oliveira-Sales, E. B., Nishi, E. E., Carillo, B. A., Dolnikoff, M. S., Bergamaschi, C. T., and Campos, R. R. (2009). Oxidative stress in the sympathetic premotor neurons contributes to sympathetic activation in renovascular hypertension. Am. J. Hypertens. 22, 484-492.

Osborn, J. W., Fink, G. D., Sved, A. F., Toney, G. M., and Raizada, M. K. (2007). Circulating angiotensin II and dietary salt: converging signals for neurogenic hypertension. Curr. Hypertens. Rep. 9, 228-235.

Patel, K., Li, Y. F., and Hirooka, Y. (2001). Role of nitric oxide in central sympathetic outflow. Exp. Biol. Med. 226, 814-824.

Peterson, J. R., Sharma, R. V., and Davisson, R. L. (2006). Reactive oxygen species in the neuropathogenesis of hypertension. Curr. Hypertens. Rep. 8, 232-241.

Pilowsky, P. M., and Goodchild, A. K. (2002). Baroreceptor reflex pathways and neurotransmitters: 10 years on. J. Hypertens. 20, 1675-1688.

Pliquett, R. U., Comish, K. G., and Zucker, I. H. (2003). Statin therapy restores sympathovagal balance in experimental heart failure. J. Appl. Physiol. 95, 700-704.

Prior, L. J., Eikelis, N., Armitage, J. A., Davern, P. J., Burke, S. L., Montani, J. P., Barzel, B., and Head, G. A. (2010). Exposure to a high-fat diet alters leptin sensitivityand elevates renal sympathetic nerve activity and arterial pressure in rabbits. Hypertension 55, 862-868.

Rahmouni, K., Correia, M. L., Haynes, W. G., and Mark, A. L. (2005). Obesity-associated hypertension: new insights into mechanisms. Hypertension 45, 9-14.

Reja, V., Goodchild, A. K., Phillips, J. K., and Pilowsky, P. M. (2006). Upregulation of angiotensin AT1 receptor and intracellular kinase gene expression in hypertensive rats. Clin. Exp. Pharmacol. Physiol. 33, 690-695.

Shi, P., Diez-Freire, C., Jun, J. Y., Qi, Y., Katovich, M. J., Li, Q., Sriramula, S., Francis, J., Summers, C., and Raizada, M. K. (2010). Brain microglial cytokines in neurogenic hypertension. Hypertension 56, 297-303.

Shinohara, K., Hirooka, Y., Ogawa, K., Kishi, T., Yasukawa, K., Utsumi, H., and Sunagawa, K. (2012). Combination therapy of olmesartan and azelnidipine inhibits sympathetic activity associated with reducing oxidative stress in the brain of hypertensive rats. Clin. Exp. Hypertens. doi: 10.3109/10641963. 2012.666603. [Epub ahead of print].

Siddiqi, L., Joles, J. A., Oey, P. L., and Blankestijn, P. J. (2011). Atorvastatin reduced sympathetic activity in patients with chronic kidney disease. J. Hypertens. 29, 2176-2180.

Simplicity HTN-2 Investigators. (2010). Renal sympathetic denervation in patients with treatmentresistant hypertension (the simplicity HTN-2 trail): a randomized controlled trial. Lancet 376, 1903-1909.

Sinski, M., Lewandowsk, J., Ciarka, A., Bidiuk, J., Abramczyk, P., Dobosiewicz, A., and Gaciong, Z. (2009). Atorvastatin reduced sympathetic activity and increases baroreceptor reflex sensitivity in patients with hypercholesterolemia and systemic arterial hypertension. Kardiol. Pol. 67, 613-620.

Stella, A., Golin, R., Genovesi, S., and Zanchetti, A. (1987). Renal reflexes in the regulation of blood pressure and sodium excretion. Can. J. Physiol. Pharmacol. 65, 1536-1539.

Stocker, S. D., Meador, R., and Adams, J. M. (2007). Neurons of the rostral ventrolateral medullacontribute to obesity-induced hypertension in rats. Hypertension 49, 640-646.

Sun, J., Druhan, L. J., and Zweler, J. L. (2010). Reactive oxygen and nitrogen species regulate inducible nitric oxide synthase function shifting the balance of nitric oxide and superoxide production. Arch. Biochem. Biophys. 494, 130-137.

Sved, A. F., Ito, S., and Sved, J. C. (2003). Brainstem mechanisms of hypertension: role of the rostral ventrolateral medulla. Curr. Hypertens. Rep. 5, 262-268.

Tai, M. H., Wang, L. L., Wu, K. L. H., and Chan, J. Y. H. (2005). Increased superoxide anion in rostral ventrolateral medulla contributes to hypertension in spontaneously hypertensive rats via interactions with nitric oxide. Free Rad. Biol. Med. 38, 450-462.

Tsuchihashi, T., Kagiyama, S. Matsumura, K., Abe, I., and Fujishima, M. (1999). Effects of chronic oral treatment with imidapril and TCV-116 on the responsiveness to angiotensin II in ventrolateral medulla of SHR. J. Hypertens. 17, 917-922.

Umemoto, S., Tanaka, M., Kawahara, S., Kubo, M., Umeji, K., Hashimoto, R., and Matsuzaki, M. (2004). Calcium antagonist reduces oxidative stress by upregulating $\mathrm{Cu} / \mathrm{Zn}$ superoxide dismutase in stroke-prone spontaneously hypertensiverats. Hypertens. Res. 27 877-885.

Wang, G., Anrather, J., Huang, J., Speth, R. C., Pickel, V. M., and Iadecola, C. (2004). NADPH oxidase contributes to angiotensin II signaling in the nucleus tractus solitarius. J. Neurosci. 24, 5516-5524.

Wang, G., Anrather, J., Glass, M. J., Tarsitano, J., Zhou, P., Frys, K. A., Pickel, V. M., and Iadecola, C. (2006). Nox2, Ca2+, and protein kinase $\mathrm{C}$ play a role in angiotensin II-induced free radical production in nucleus tractus solitarius. Hypertension 48, 482-489.

Wang, J. M., Tan, J., and Leenen, F. H. H. (2003). Central nervous system blockade by peripheral administration of AT1 receptor blockers. J. Cardiovasc. Pharmacol. 41, 593-599.

Wassmann, S., Laufs, U., Muller, K., Konkol, C., Ahlbory, K., Baumer, A. T., Linz, W., Bohm, M., and Nickenig, G. (2002). Cellular antioxidant effects of atorvastatin in vitro and in vivo. Arterioscler. Thromb. Vasc. Biol. 22, 300-305.

Ye, S., Zhong, H., and Campese, V. M. (2006). Oxidative stress mediates the sympathetic nerve activity in the phenol renal injury model of hypertension. Hypertension 48, 309-315.

Yu, Y., Zhang, Z. H., Wei, S. G., Serrats, J., Weiss, R. M., and Felder, R. B. (2010). Brain perivascular macrophages and the sympathetic response to inflammation in rats after myocardial infarction. Hypertension 55, 652-659.

Zanzinger, J. (2002). Mechanisms of action of nitric oxide in the brain stem: role of oxidative stress. Auton. Neurosci. 98, 24-27.

Zielonka, J., Zielonka, M., Sikora, A., Adamus, J., Joseph, J., Hardy, M., Ouari, O., Dranka, B. P., and Kalyanaraman, B. (2012). Global profiling of reactive oxygen and nitrogen species in biological systems: high-throughput realtime analysis. J. Biol. Chem. 287, 2984-2995.

Zimmerman, M. C., Dunlay, R. P., Lazartigues, E., Zhang, Y. Sharma, R. V., Engelhardt, J. F, and Davisson, R. L. (2004a). Requirement for Racl-dependent NADPH oxidase in the cardiovascular and dipsogenic actions of angiotensin II in the brain. Circ. Res. 95, 532-539.

Zimmerman, M. C., Larzartigues, E., Shrama, R. V., and Davisson, R. L. (2004b). Hypertension caused by angiotensin II infusion involves increased superoxide production in the central nervous system. Circ. Res. 95, 210-216.

Zimmerman, M. C., and Zucker, I. H. (2009). Mitochondrial dysfunction and mitochondria-produced reactive oxygen species: new aspects for neurogenic hypertension? Hypertension. 53, 112-114.

Zucker, I. H., Schultz, H. D., Patel, K. P., Wang, W., and Gao, L. (2009). Regulation of central angiotensin type 1 receptors and sympathetic outflow in heart failure. Am. J. Physiol. 297, H1557-H1566.

Conflict of Interest Statement: The authors declare that the research was conducted in the absence of any commercial or financial relationships that could be construed as a potential conflict of interest.

Received: 22 May 2012; accepted: 30 July 2012; published online: 17 August 2012. Citation: Kishi T and Hirooka Y (2012) Oxidative stress in the brain causes hypertension via sympathoexcitation. Front. Physio. 3:335. doi: 10.3389/fphys. 2012.00335

This article was submitted to Frontiers in Oxidant Physiology, a specialty of Frontiers in Physiology.

Copyright (c) 2012 Kishi and Hirooka. This is an open-access article distributed under the terms of the Creative Commons Attribution License, which permits use, distribution and reproduction in other forums, provided the original authors and source are credited and subject to any copyright notices concerning any third-party graphics etc. 